\title{
Ghana's Preparedness Now and For Future Pandemics
}

\section{Harry Akligoh}

The presidential address to Ghanaians in the face of the novel coronavirus pandemic have seen repeats of words including; 3Ts (Test, Trace and Treat), Scientific data and Africa's capacity to go into vaccine and Personal Protective Equipment (PPE) manufacturing. Excellent as these addresses may be, there are chronic and inherent systems challenges that are exposing our fundamentals as a country to better fight and defeat the COVID-19 pandemic caused by the SARS-COV-2.

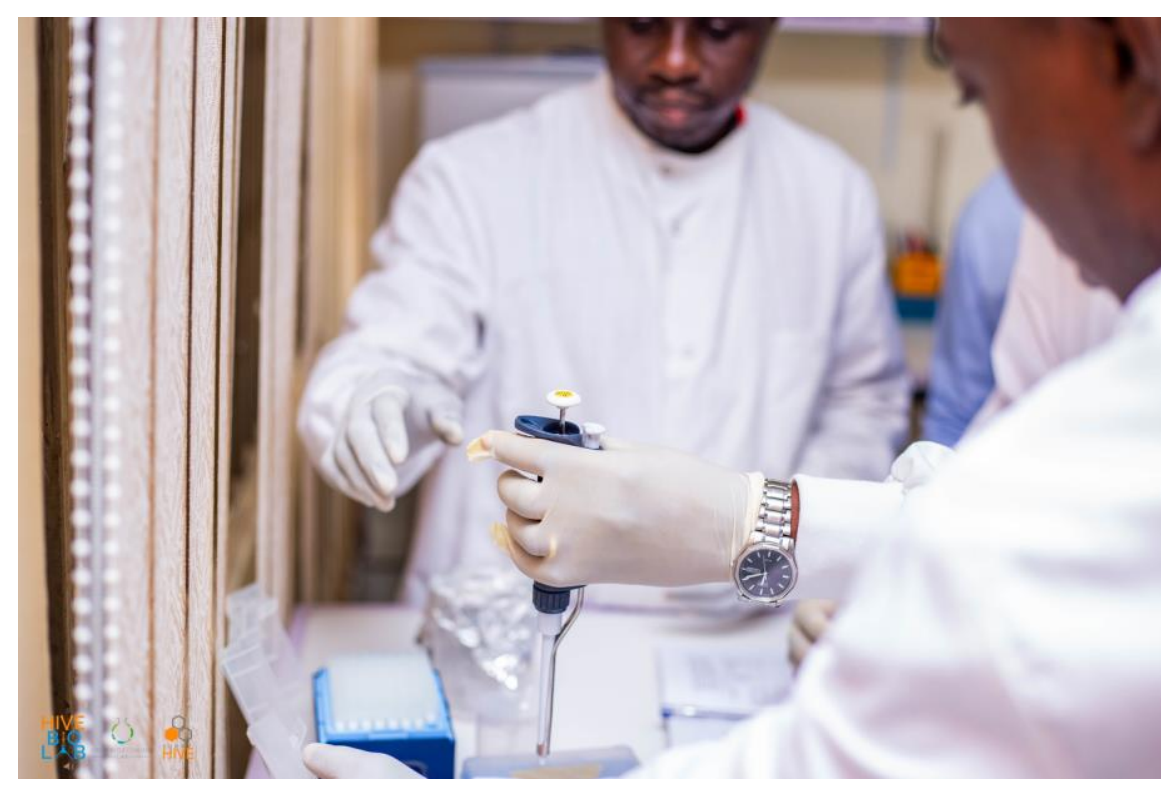

Th

It is important to emphasize that laboratory services are key to the quality of healthcare (WHO, n.d.) but have remained a historically neglected component of the health systems in low-and middle-income countries of which Ghana is not an exception. The effectiveness and utilization of the 3Ts (Test, Trace and Treat) in the fight against COVID19 have not achieved the desired outcome because of bottlenecks that exists in Ghana's laboratory and diagnostic industry.

The successes of robust health systems are largely due to evidence-based practices and diagnosis which are typical of countries in Europe and America. However, current health policies in Ghana still date back to the 90s with lots of monopoly, imperialism and redundancy within government institutions and agencies mandated to deliver her health agenda. 


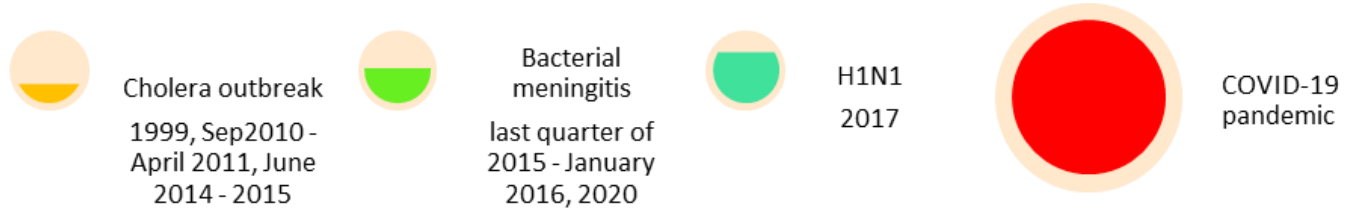

Ghana's historical Outbreak map

In the past decade and years before, Ghana has seen major outbreaks including cholera (Ohene-Adjei et al., 2017)(1999, Sep 2010 - April 2011, June 2014 - 2015), bacterial meningitis (last quarter of 2015 - 2016, 2020) and H1N1 (2017) causing the lives of many, yet failed to learn, develop and strengthen her ailing health systems. Again, in 2014 some countries including the DR Congo and Nigeria in the West African subregion were plagued with the Ebola Virus Disease (EVD) which claimed the lives of many. However, following recommendations from WHO and experts on the possibilities of the EVD been transmitted into Ghana, government in its preparedness plans decided to set up isolation centers (many of which were abandoned later), bought and branded vehicles for public education and held several meetings where huge monies were paid to attendees as sitting allowance.

Actions and strategies highlighted above invariably characterize most action plans instituted as public health response measures in any outbreak situation in Ghana and such practices have crippled and left the Ghanaian health system porous, fragile and not capable of handling major outbreaks/pandemics. It is therefore, not a surprise that we are struggling as a country in understanding the incidence of COVID-19 in Ghana due to the lack of adequate systems, health and testing infrastructure. It will even become worse and ravaging if we do not act immediately. 


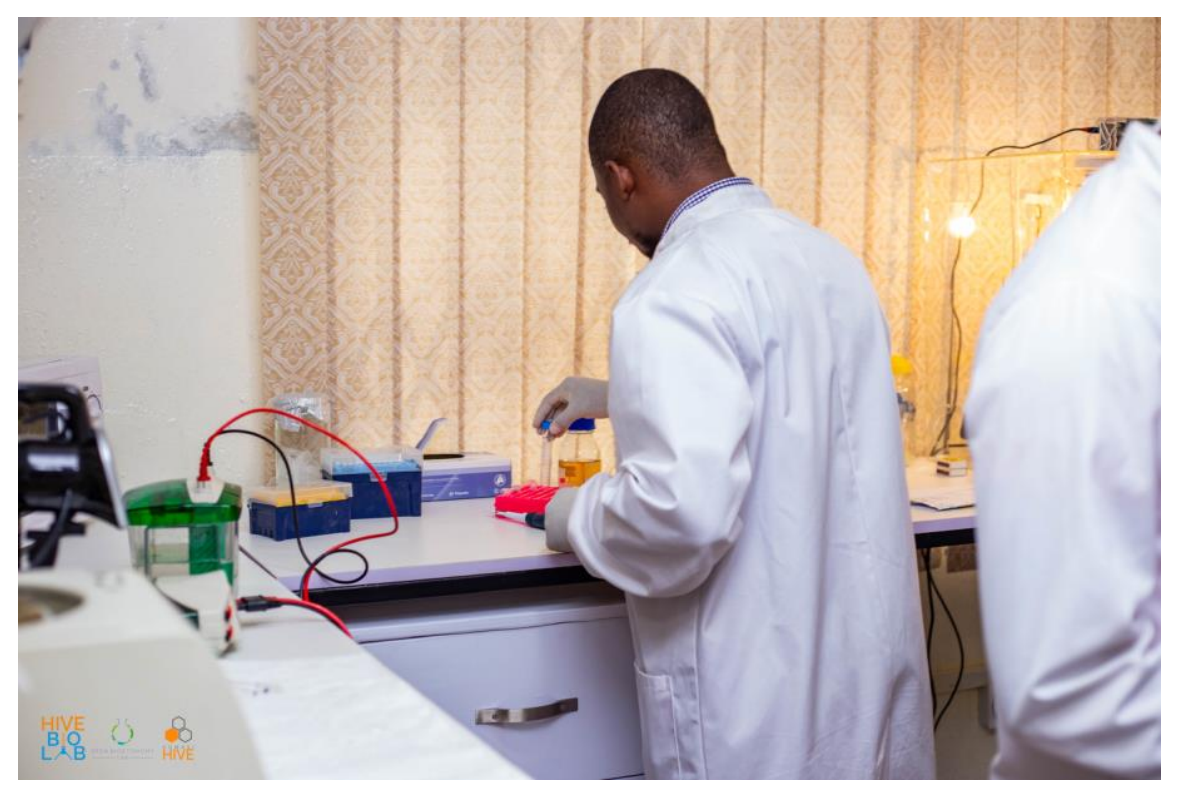

Scientist working in the lab

Therefore, in an effort to overcome and address the ailing laboratory infrastructure system gap within the Ghanaian health system, the Government of Ghana through the Ministry of Health (MoH) partnered with the Centre for Disease Control (CDC), Atlanta, USA a couple of years ago to draft the National Laboratory Policy in 2013, a document which when implemented will strengthen medical laboratories in Ghana. However, this document has since been lying in the shelves of the $\mathrm{MoH}$.

Amazingly, in the 8th presidential address to the nation, the president, H.E Nana Addo Danquah Akuffo-Addo mentioned key strategies government will be rolling out as the country's preparedness plans for future outbreaks and pandemics. He mentioned among many things the establishment of 88 hospitals, infectious disease facilities and the establishment of the Ghana Center for Disease Control. Though these plans are laudable and aimed at creating the right infrastructural capacity for the country in future pandemics, it is important to note that good systems and effective policies are critical at achieving better health outcomes which we currently lack as a country. It is for this reason that I propose the recommendations below to aid government while it is still in the process of consolidating a solid preparedness plan for handling future pandemics in Ghana now and in the future. The recommendations include;

1. Investment in biomedical science research and development capacities by allocating at least $1 \%$ or more of Ghana's GDP.

2. Pass the National Laboratory Policy into a bill and operationalize it to strengthen existing medical laboratories to capacities where they are ready to serve as testing centers in future outbreaks or pandemics.

3. Establish a National Laboratory Directorate at the Ministry of Health to oversee laboratory services in the country and 
4. Resolve labor related issues within the healthcare sector by carefully reviewing salary payment structures and passing laws to define the constitutional job requirements of each healthcare workforce in the country.

Therefore, to conclude, it is imperative to note that the fight against COVID-19 and other pandemics starts with an effective and implementable preparedness plan.

\section{References}

Strategic framework for strengthening health laboratory services 2016-2020.

https://extranet.who.int/iris/restricted/bitstream/handle/10665/254902/EMROPUB_20

17_EN_19612.pdf;jsessionid=54488FCC8C067DF772C9E16C896CE0C1? sequence=1.

https://extranet.who.int/iris/restricted/bitstream/handle/10665/254902/EMROPUB_20

17_EN_19612.pdf;jsessionid=54488FCC8C067DF772C9E16C896CE0C1? sequence=1

Epidemiological link of a major cholera outbreak in Greater Accra region of Ghana 2014. (2017). BMC Public Health, 17(1). https://doi.org/10.1186/s12889-017-4803-9

Epidemiological link of a major cholera outbreak in Greater Accra region of Ghana, 2014. https://bmcpublichealth.biomedcentral.com/articles/10.1186/s12889-017-4803-9.

https://bmcpublichealth.biomedcentral.com/articles/10.1186/s12889-017-4803-9 